\title{
Peliosis of the spleen: possible association with chronic renal failure and erythropoietin therapy
}

\author{
KY Lam, ACL Chan, TM Chan
}

\begin{abstract}
Summary
Splenic peliosis was identified at necropsy in a 62-year-old woman receiving continuous ambulatory peritoneal dialysis for end-stage renal failure, and erythropoietin therapy for uraemia and anaemia. The immediate cause of death was arrhythmia related to ischaemic heart disease, following an episode of intramuscular haematoma (secondary to platelet dysfunction). The unusual association between peliosis and renal failure, and possibly erythropoietin therapy, is discussed.
\end{abstract}

Keywords: peliosis, spleen, erythropoietin

Peliosis is a rare lesion characterised by widespread blood-filled cystic spaces, which is most often detected in the liver and the spleen, ${ }^{1-23}$ but also occasionally detected in other organs including lung, lymph node, bone marrow, kidney, adrenal gland, gastrointestinal tract and parathyroid gland. . $^{2,8,16,18,24,25}$ The condition is often clinically silent, but can predispose to rupture of the liver or spleen. ${ }^{7,10,12,20,22,23}$

We report an incidental finding of peliosis of spleen in a patient with end-stage renal failure and receiving erythropoietin therapy for uraemia and anaemia. The possible association between peliosis and erythropoietin therapy is discussed.

\section{Case report}

A 62-year-old Chinese woman presented in June 1990 with end-stage renal failure and bilateral small kidneys. Except for a three-year history of gouty arthritis, her past health was unremarkable. At presentation, she had normochromic normocytic anaemia with a haemoglobin level of $6.3 \mathrm{~g} / \mathrm{dl}$, white cell count of $6.2 \times 10^{9} / 1$, and platelet count of $195 \times 10^{9} / 1$. She was started on continuous ambulatory peritoneal dialysis, with serum urea and creatinine levels maintained at around 25 $\mathrm{mmol} / \mathrm{l}(70.0 \mathrm{mg} / \mathrm{dl})$ and $1100 \mu \mathrm{mol} / \mathrm{l}(12.4 \mathrm{mg}$ $\mathrm{dl})$, respectively. She remained uneventful for two years, with stable serum biochemistry and haemoglobin levels, not requiring any blood transfusion. Thereafter, she developed progressive anaemia, necessitating blood transfusion with increasing frequency up to one unit per month. Investigations including gastroscopy and sigmoidoscopy showed no evidence of gastrointestinal blood loss. The levels of iron, ferritin, and aluminium were within normal limits, while that of parathyroid hormone was elevated to $298 \mathrm{pg} / \mathrm{ml}$ (normal range 10-50). She was started on erythropoietin therapy (2000 units subcutaneous injection twice weekly) in July 1993. In August 1993, she was admitted because of abdominal intramuscular haematoma after minor trauma. Complete blood picture showed a haemoglobin level of $5.4 \mathrm{~g} / \mathrm{dl}$, white cell count of $8.7 \times 10^{9} / 1$ and platelet count of $115 \times 10^{9} / 1$. Prothrombin time and activated partial thromboplastin time were within the normal range. She had not received any medication that could predispose to bleeding diathesis. She was transfused and her haemodynamic condition was stable. While being investigated for her intramuscular haemorrhage, she developed arrhythmia with sudden cardiac arrest shortly after admission.

\section{Post mortem findings}

Autopsy examination showed a $20-\mathrm{cm}$ intramuscular haematoma within the anterior abdominal wall. Both kidneys were small and nodular hyperplasia of the parathyroid glands was present. There was concentric left ventricular hypertrophy and coronary atherosclerosis with $75 \%$ obstruction of the right coronary artery. There was no evidence of myocardial infarction. The cause of death was arrhythmia, probably related to ischaemic heart disease following an episode of intramuscular haematoma. The bleeding tendency was probably due to mild thrombocytopenia and platelet dysfunction related to chronic renal failure.

The spleen was slightly enlarged and weighed $260 \mathrm{~g}$. Numerous blood-filled cystlike spaces were scattered throughout the cut surface. These cysts measured from 1 to $5 \mathrm{~mm}$ in diameter. They were round, oval or somewhat irregular and were filled with partially or totally clotted blood (figure). Microscopic examination showed that these cystic spaces lacked endothelial lining. This was confirmed by negative immunostaining of the 'cyst wall' for endothelial markers, factor VIII related antigen (at a dilution of 1:300 from Dakopatts, Glostrup, Denmark) and CD31 (at a dilution of 1:20 from Dako, Kyoto, Japan). There was no evidence of necrosis or significant haemosiderin deposition. The features were consistent with peliosis of the spleen. The other organs including the liver showed no evidence of peliosis. 


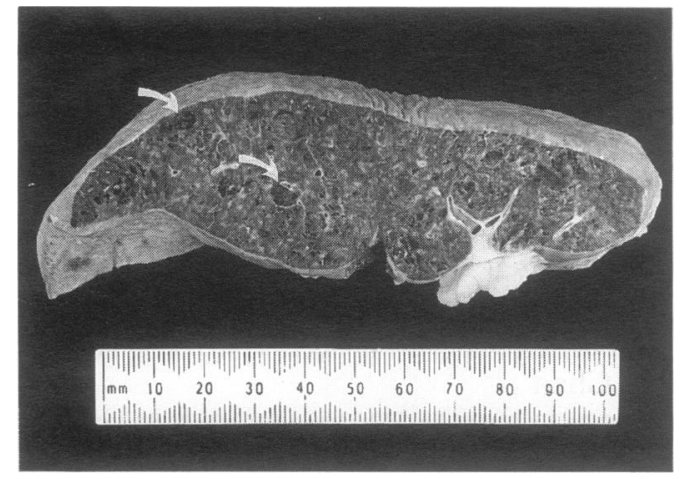

Figure Cut surface of the spleen with numerous blood-filled cystic spaces measuring up to $5 \mathrm{~mm}$ in diameter (white arrows)

\section{Discussion}

Splenic peliosis refers to the macroscopic and microscopic findings of multiple blood-filled cystic spaces in the spleen usually without an endothelial lining. The entity must be differentiated from congestion, vascular tumours and tumour-like vascular lesions of the spleen including haemangioma, angiosarcoma, Kaposi's sarcoma and bacillary angiomatosis. Congestion of the spleen is diffuse rather than focal, and the cordal-sinusoidal relationship remains normal. Cavernous haemangioma is the most common benign vascular tumour of the spleen, but the vascular spaces are lined by endothelial cells and are separated by bands of connective tissue. Angiosarcoma is characterised by anastomosing vascular channels lined by atypical endothelial cells with frequent tufting. Kaposi's sarcoma has the characteristic interlacing pattern of spindle cells with cleft-like spaces and hyaline bodies. Bacillary angiomatosis in immunocompromised patients is caused by the bacteria Rochalimaea henselae. ${ }^{26}$ It is distinguished from peliosis by the presence of neutrophils and bacterial clumps, the latter can be demonstrated by Warthin Starry stain.

Forty cases of splenic peliosis have been documented in the English literature (table 1). ${ }^{1-23}$ The condition has a wide age distribution (ranging from 14 to 82) with a mean of 53 and a male to female ratio of 1.7:1. Although most of the cases were found incidentally, splenic peliosis was not just a pathological curiosity because splenic rupture was seen in $20 \%$ (eight cases). Many cases were associated with hepatic peliosis, but 23 cases of isolated splenic peliosis were identified. However, many of these cases of isolated splenic peliosis were from surgical specimens and the status of the liver might not be properly assessed. Thus, it was difficult to prove that the liver was not involved except in reports documenting autopsy findings and these included a total of 11 cases, ${ }^{13,15,16}$ including the present case.

Splenic peliosis has been mostly associated with the administration of steroids, especially anabolic steroids. ${ }^{3-6,12,13,17,19,23}$ The entity has also been reported to be associated with neoplasms (including carcinomas of lung,

\begin{tabular}{|l|}
\hline Features/causes of peliosis \\
\hline Features: \\
- an uncommon lesion \\
- in liver, spleen, lung, lymph node, bone \\
marrow, kidney, adrenal glands, \\
gastrointestinal tract and parathyroid gland \\
Proposed causes: \\
- idiopathic \\
- admission of steroids \\
- tuberculastic diseases \\
- AIDS \\
- diabetes mellitus \\
- Thronic renal failure \\
- immunotrast
\end{tabular}

Box 1

liver, cervix and colon, lymphoma, chronic myelomonocytic leukaemia and paraganglioma), ${ }^{4,9,11-13,21}$ tuberculosis, ${ }^{1}$ acquired immunodeficiency syndrome, ${ }^{15}$ diabetes mellitus, ${ }^{1}$ chronic renal failure, ${ }^{4}$ Thorotrast, ${ }^{14}$ and immunosuppressive therapy. ${ }^{7}$ Nevertheless, the aetiology is still unknown. In the present case, the patient had chronic renal failure, but it has been suggested that chronic renal failure per se was probably not responsible for peliosis as it is commonly found after renal transplantation. ${ }^{27}$ Thus, the possible role of erythropoietin should also be considered in this case.

Erythropoietin is a circulating glycoprotein composed of 165 amino acids and four oligosaccharide chains. ${ }^{28}$ The gene for the hormone has been cloned and recombinant erythropoietin has become an accepted therapy for the treatment of anaemia of chronic renal failure with well-documented beneficial effects. ${ }^{29}$ However, there are several possible adverse effects in using erythropoietin therapy. These include an increase in blood pressure, generalised seizures, and possible increased clotting of vascular access. It has never been associated with peliosis. However, the effect of erythropoietin on the cardiovascular system might lead to peliosis. Also, erythropoietin secretion is increased by androgens and the latter are strongly associated with peliosis. Thus, erythropoietin may be the mediator responsible for causing peliosis in this group of patients. The proposed theories for the pathogenesis of peliosis include congenital malformations, vascular varicosities, ruptured vessels, primary necrosis fol-

\section{Properties of erythropoietin}

- a circulating glycoprotein

- composed of 165 amino acids and four oligosaccharide chains

- secreted by the kidney

- used for treatment of anaemia associated with chronic renal failure

- adverse effects include increased blood pressure, generalised seizures, and increased clotting of vascular access

Box 2 
Table Summary of reported cases of splenic peliosis

\begin{tabular}{|c|c|c|c|c|}
\hline $\operatorname{Ref}$ & Sex/age & Other site of involvement & Associated condition & Remarks \\
\hline \multirow[t]{2}{*}{1} & $M / 35$ & liver & diabetes mellitus & - \\
\hline & $\mathrm{M} / 57$ & liver & tuberculosis & - \\
\hline 2 & $\mathrm{~F} / 36$ & $\begin{array}{l}\text { liver, lymph node, bone } \\
\text { marrow }\end{array}$ & - & - \\
\hline 3 & $M / 14$ & liver & steroid therapy & ruptured spleen \\
\hline \multirow[t]{4}{*}{4} & $\mathrm{~F} / 41$ & liver & steroid therapy, lymphoma & - \\
\hline & $\mathrm{M} / 74$ & liver & steroid therapy & ruptured spleen \\
\hline & $\mathrm{M} / 38$ & - & steroid therapy, chronic renal failure & liver not examined \\
\hline & $\mathrm{M} / 52$ & - & steroid therapy, alcoholism & liver not examined \\
\hline \multirow[t]{2}{*}{5} & $\mathrm{M} / 46$ & liver & steroid therapy & - \\
\hline & $M / 48$ & liver & steroid therapy & - \\
\hline \multirow[t]{2}{*}{6} & $M / 46$ & liver & steroid therapy & - \\
\hline & $\mathrm{M} / 48$ & liver & steroid therapy & - \\
\hline 7 & $\mathrm{M} / 21$ & - & renal transplant & $\begin{array}{l}\text { ruptured spleen, liver grossly } \\
\text { unremarkable }\end{array}$ \\
\hline 8 & $\mathrm{M} / 70$ & $\begin{array}{l}\text { liver, lung, lymph node, } \\
\text { bone marrow, kidney, } \\
\text { adrenal gland, } \\
\text { digestive tract }\end{array}$ & past history of tuberculosis & - \\
\hline 9 & $\mathrm{M} / 79$ & - & myelofibrosis & - \\
\hline 10 & $\mathrm{~F} / 48$ & - & drug addict, alcoholism & ruptured spleen, liver not examined \\
\hline 11 & $F / 61$ & liver & myeloma, steroid therapy & - \\
\hline 12 & $\mathrm{M} / 62$ & - & steroid therapy, leukaemia & ruptured spleen, liver biopsy done \\
\hline \multirow[t]{10}{*}{13} & $\mathrm{~F} / 73$ & - & history of carcinoma of cervix & - \\
\hline & $\mathbf{M} / 63$ & - & - & - \\
\hline & $M / 68$ & - & steroid therapy & - \\
\hline & $\mathrm{M} / 17$ & liver & steroid therapy & - \\
\hline & $\mathrm{F} / 68$ & - & $\begin{array}{l}\text { history of carinoma of cervix, post- } \\
\text { radiotherapy }\end{array}$ & - \\
\hline & $\mathbf{F} / 76$ & - & lung cancer, anti-cancer drugs & - \\
\hline & $\mathrm{M} / 79$ & liver & colon cancer, anti-cancer drugs & - \\
\hline & $\mathrm{F} / 59$ & - & lung cancer, anti-cancer drugs & - \\
\hline & $\mathrm{M} / 50$ & - & liver cancer, anti-cancer drugs, cirrhosis & - \\
\hline & $\mathrm{M} / 82$ & - & steroid therapy, myeloma, anti-cancer drugs & - \\
\hline 14 & $\mathrm{~F} / 60$ & liver & Thorotrast & - \\
\hline 15 & $M / 46$ & - & cirrhosis & - \\
\hline 16 & $\mathrm{M} / 38$ & liver, lymph node & AIDS & - \\
\hline \multirow[t]{2}{*}{17} & $\mathrm{~F} / 50$ & - & $\begin{array}{l}\text { steroid therapy, splenic haematoma, idiopathic } \\
\text { thrombocytopenic purpura }\end{array}$ & liver not examined \\
\hline & $\mathrm{F} / 80$ & - & $\begin{array}{l}\text { steroid therapy, splenic haematoma, idiopathic } \\
\text { thrombocytopenic purpura }\end{array}$ & liver not examined \\
\hline 18 & $\mathrm{~F} / 52$ & liver, lymph node & past history of tuberculosis & ruptured spleen and liver \\
\hline 19 & $\mathrm{~F} / 32$ & - & steroid therapy & liver biopsy done \\
\hline 20 & $\mathbf{F} / 37$ & - & - & liver not examined \\
\hline 21 & $M / 44$ & - & paraganglioma & liver not examined \\
\hline 22 & $\mathbf{M} / 37$ & - & - & ruptured spleen, liver not examined \\
\hline 23 & $M / 68$ & - & steroid therapy & ruptured spleen, liver not examined \\
\hline Present & $\mathrm{F} / 65$ & - & chronic renal failure, erythropoietin therapy & - \\
\hline
\end{tabular}

lowed by haemorrhage, and dual origins from inflamed veins that bulge into parenchyma and from parenchymal necrosis. ${ }^{30}$ The effects of erythropoietin on the microvasculature of the spleen are unknown. In the present case, there was no endothelial lining noted in the blood cysts and there was no necrosis in the parenchyma. Thus it is unlikely that erythropoietin acted through these mechanisms. It is also worth noting that erythropoietin can be extracted from the spleen of a normal person although the spleen is not the site of its production. ${ }^{27}$ In summary, we report a case of asymptomatic splenic peliosis occurring in a patient with chronic renal failure receiving erythropoietin. Although the relationship between erythropoietin and splenic peliosis may be coincidental, clinicians and patho-

1 Hamilton FT, Lubitz JM. Peliosis hepatis: report of three cases, with discussion of pathogenesis. Arch Pathol 1952; 54: 564-71.

2 Kent G, Thompson JR. Peliosis hepatis: involvement of reticuloendothelial system. Arch Pathol 1961; 72: 66-72.

\section{Learning/summary points}

- splenic peliosis is an unusual condition which may be complicated by ruptured spleen

- 40 cases have been documented in the English literature

- the lesion may be related to the administration of steroids and other chronic diseases

- possible association between splenic peliosis with renal failure and erythropoietin therapy is suggested

Box 3

logists alike should be aware of this as splenic peliosis may occasionally lead to rupture with haemoperitoneum.

3 Benjamin DR, Shunk B. A fatal case of peliosis of the live and spleen. Am $\mathcal{F}$ Dis Child 1978; 132: 207-8.

4 Taxy JB. Peliosis: a morphologic curiosity becomes an iatrogenic problem. Hum Pathol 1978; 9: 331-40. 
5 Chopra S, Edelstein A, Koff RS, Zimelman AP, Lacson A, Neiman RS. Peliosis hepatis in hematologic disease: repor of two cases. FAMA 1978; 240: 1153-5.

6 Lacson A, Berman LD, Neiman RS. Peliosis of the spleen Am $\mathcal{f}$ Clin Pathol 1979; 71: 586-90.

7 Parsons MA, Slater D, Platts M, Fox M. Splenic peliosis associated with rupture in a renal transplant patient. Postgrad Med F 1980; 56: 796-7.

8 Ichijima K, Kobashi Y, Yamabe H, Fujii Y, Inoue Y. Peliosis hepatis: an unusual case involving multiple organs Acta Pathol Jpn 1980; 30: 109-20.

9 Warfel KA, Ellis GH. Peliosis of the spleen: report of a case Warfel KA, Ellis GH. Peliosis of the spleen: report of a case
and review of the literature. Arch Pathol Lab Med 1982; 106: and review 100 .

10 Garcia RL, Khan MK, Berlin RB. Peliosis of the spleen with rupture. Hum Pathol 1982; 13: 177-9.

11 Asano S, Wakasa H, Kaise S, Nishimaki T, Kasukawa R. Peliosis hepatis: report of two autopsy cases with a review of literature. Acta Pathol fpn 1982; 32: 861-77.

12 Diebold J, Audouin J. Peliosis of the spleen: report of a case associated with chronic myelomonocytic leukaemia, presenting with spontaneous splenic rupture. Am f Surg Patho 1983; 7: 197-204.

13 Tada T, Wakabayashi T, Kishimoto H. Peliosis of the spleen. Am f Clin Pathol 1983; 79: 708-13.

14 Dejgaard A, Krogsgaard K, Jacobsen M. Veno-occlusive disease and peliosis of the liver after thorotrast administration. Virchows Arch 1984; 40: 87-94.

15 Bleiweiss IJ, Thung SN, Goodman JD. Peliosis of the spleen in a patient with cirrhosis of the liver. Arch Pathol Lab Med in a patient with cirrh

16 Czapar CA, Weldon-Linne CM, Moore DM, Rhone DP. Czapar CA, Weldon-Linne CM, Moore DM, Rhone DP.
Peliosis hepatis in the acquired immunodeficiency syndrome. Arch Pathol Lab Med 1986; 110: 611-3.

17 Diebold J, Audouin J. Association of splenoma, peliosis and lipid histiocytosis in spleen or accessory spleen removed in 2 patients with chronic idiopathic thrombocytopenia purpura after long term treatment with steroids. Pathol Res Pract 1988; 183: 446-52.
18 Kubosawa $\mathrm{H}$, Konno A, Komatsu T, Ishige H, Kondo $\mathrm{Y}$. Peliosis hepatis: an usual case involving the spleen and the lymph nodes. Acta Pathol fpn 1989; 39: 212-5.

19 Cochrane LB, Freson M. Peliosis of the spleen. Gastrointest Radiol 1991; 16: 83-4.

20 Gabor S, Back F, Csiffary D. Peliosis lienis: uncommon cause of rupture of the spleen. Pathol Res Pract 1992; 188: 380-2.

21 Engel P, Tjalve E, Horn T. Peliosis of the spleen associated with a paraganglioma. Acta Radiol 1993; 34: 148-9.

$22 \mathrm{Kohr}$ RM, Haendiges M, Taube RR. Peliosis of the spleen: a rare cause of spontaneous splenic rupture with surgical implications. Am Surg 1993; 59: 197-9.

23 Tsuda K, Nakamura H, Murakami T, et al. Peliosis of the spleen with intraperitoneal hemorrhage. Abdom Imaging spleen with intrape

24 Castelli MJ, Armin AR, Orfei E. Parathyroid peliosis: report of a case and review of the literature. Pediatr Pathol 1986; 6: $127-30$.

25 Lie JT. Pulmonary peliosis. Arch Pathol Lab Med 1985; 109: 878-9.

26 Slater LN, Weelch DF, Min KW. Rochalimea henselae causes bacillary angiomatosis and peliosis hepatis. Arch Intern Med 1992; 152: 602-6.

27 Degott C, Rueff B, Kreis H, Duboust A, Potet F, Benhamou JP. Peliosis hepatis in recipients of renal transplants. Gut 1978; 19: 748-53.

28 Ganong WF. Other endocrine organs. In: Review of medical physiology, 16th edn. USA: Appleton \& Lange, 1993; physiology,

29 Eschbach JW, Aquiling T, Haley NR, Fan MH, Blagg CR. The long-term effects of recombinant human erythropoietin on the cardiovascular system. Clin Nephrol 1992; 38 (suppl): on the cardio

30 Trites AEW. Peliosis hepatis: report of a case. Arch Pathol 1957; 63: 183-186.

\title{
Pellagra complicating Crohn's disease
}

\author{
Irshad Zaki, Leslie Millard
}

\begin{abstract}
Summary
We report a 53-year-old patient with clinical features of pellagra as a complication of Crohn's disease. His symptoms improved rapidly on taking oral nicotinic acid and vitamin $B$ complex. We suggest the paucity of reported cases of pellagra in Crohn's disease is a reflection of poor recognition of this complication.
\end{abstract}

Keywords: pellagra, Crohn's disease

Pellagra is derived from the Italian words 'pelle agra' meaning rough skin and was first described in 1735 by the Spanish physician Casal. The disease is a result of deficiency of nicotinamide or disturbance of other pathways of tryptophan metabolism. Pellagra was originally of epidemic proportions in areas where maize was the principal component of the diet. However, with appropriate food supplements, pellagra is now rarely seen in developed countries, but is still relatively common in poorer areas. Other causes include carcinoid syndrome, treatment with isoniazid and Hartnup disease.

\section{Case report}

A 53-year-old caucasian man presented with a two-month history of a pruritic photosensitive

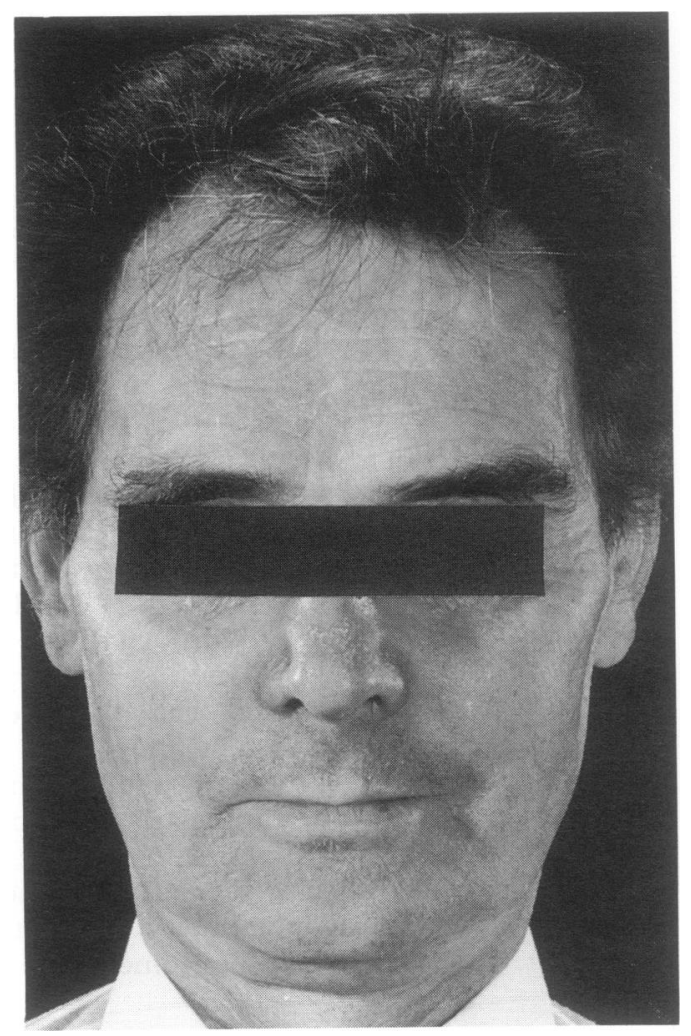

Figure The patient at presentation with an erythematous rash worst on his nose, upper lip and chin. Fine surface wrinkling and superficial scaling is also visible. 